10. Gotschlich EC. Rey M. Triau R, Sparks KJ. Quantitative determination of human immune response to immunization with meningococcal vaccines. J Clin Invest 1972:51:89-96.

11. Lepow ML, Goldschneider I. Gold R. Randolph M. Gotschlich EC. Persistence of antibody following immunization of children with groups $\mathrm{A}$ and $\mathrm{C}$ meningococcal polysaccharide vaccines. Pediatrics 1977:60;673-80.

12. Gold R. Lepow ML. Goldschneider I. Draper TF, Gotschlich EC. Kinetics of antibody production to group $\mathrm{A}$ and group $\mathrm{C}$ meningococ- cal polysaccharide vaccines administered during the first six years of life: prospects for routine immunization of infants and children. $J$ Infect Dis 1979:140:690-7.

13. Kayhty H, Karanko V, Peltola H, Sarna S, Makela PH. Serum antibodies to capsular polysaccharide vaccine of group A Neisseria meningitidis followed for three years in infants and children. $\mathbf{J}$ Infect Dis 1980;142:86I-8

14. Williamson AW. Greenwood BM. Impairment of the immune response to vaccination after acute malaria. Lancet 1978:1:1328-9.

\title{
Ribotyping of Pseudomonas aeruginosa Strains Isolated from Surgical Intensive Care Patients
}

\author{
Eva Gruner, Andrea Kropec, Johannes Huebner, \\ Martin Altwegg, and Franz Daschner
} Institute of Medical Microbiology. University of Zurich, Swituetland:
Department of Environmental Medicine and Hospital Epidemiolog!:
University Hospital. Freiburg. Germany.

\begin{abstract}
To elucidate the sources of Pseudomonas aeruginosa on a surgical intensive care unit, rDNA restriction fragment length polymorphism analysis (ribotyping) was applied to analyze strains isolated during a 4-month prospective study. Samples included 1635 from 153 patients, 2463 from 97 staff members, and 581 from the environment. Only 18 patients were colonized. Isolation from their animate and inanimate environment was very low, with 3 and 2 samples, respectively, being positive. Samples from tap water were negative. Ribotyping could easily distinguish 16 different digest patterns with identical follow-up isolates of the same patient. Horizontal transmission occurred only twice. The discriminatory power of ribosomal DNA in differentiating strains was dependent on the restriction enzymes used; among eight different enzymes, $P v u I I$ was the most sensitive, producing 15 different patterns. Ribotyping showed high sensitivity in typing $P$. aeruginosa isolates and confirmed that colonization occurs from endogenous rather than from exogenous sources.
\end{abstract}

Pseudomonas aeruginosa is currently the fourth most frequently isolated nosocomial pathogen, accounting for $9.9 \%$ of all hospital-acquired infections, mainly surgical wound infections and gram-negative bacteremias [1]. Increasing length of hospital stay, age, gastrointestinal diseases, and prior use of antibiotics may lead to higher colonization rates with $P$. aeruginosa, especially in intensive care unit (ICU) patients [2], and colonization of patients undergoing mechanical ventilation or receiving chemotherapy for neoplastic diseases often predisposes to invasive infection. Previous typing methods such as bio-, sero-, and pyocin typing as well as newer DNA-based typing systems suggested sink drains, toilets, and showers as major sources for nosocomial infections in ICUs $[3,4]$. However. although numerous investigations have been done, the routes of colonization or infection

Received 24 July 1992; revised 30 October 1992.

Reprints or correspondence: Dr. Eva Gruner. Institute of Medical Microbiology. University of Zurich, Gloriastrasse 32. P.O. Box (H-8028, Zurich. Switzerland.

The Journal of Infectious Diseases 1993;167:1216-20 (C) 1993 by The University of Chicago. All rights reserved. $0022-1899 / 93 / 6705-0037 \$ 01.00$ of this opportunistic pathogen remain largely a matter of speculation $[2,5]$.

We present an rDNA restriction fragment analysis of $P$. aenuginosa strains isolated during a 4-month prospective study on a surgical ICU of a German university hospital. Specimens were collected from both patients and personnel as well as from their inanimate environment. The incidence of colonization on admission and during hospitalization was determined, and transmission of bacteria was traced.

\section{Materials and Methods}

Situdy design. From I March to 28 June 1990, all 153 patients admitted to the surgical ICU of University Hospital, Freiburg. were screened for colonization with $P$. aeruginosa. Most were admitted after major trauma, with abdominal and skull injuries or complications of cardiovascular diseases and occasionally after organ transplantation. About $60 \%$ of the patients were directly transferred to the ICU without any previous stay on other units. Swabs from pharynx, scalp, tracheal secretions, and rectum were taken on admission and on every second day thereafter. Fifty-two percent of the patients stayed $>2$ days and were swabbed at least twice. Whenever found in other speci- 
mens than those mentioned, isolates of $P$. aeruginosa were included in the study.

The ICU has one four-bed room, two two-bed rooms, and one isolation room. Personnel (97: physicians, nurses, and secondary help) were screened every day for 1 week each month. Nasal swabs, two swabs from their gowns (abdominal region and outside of the pocket), and two RODAC plates from hands were taken each day at arbitrary hours (to prevent prior hand washing). Each patient was cared for by an individual nurse, but exceptions were possible when the ward was busy. Hand disinfection was usually carried out after handling a patient.

Swabs from the patients environment were obtained at the same time. The patient monitor and the emergency button of the respirator were chosen for this purpose because of their frequent contact with hands of personnel. Additionally, water from every water tap was cultured once a week.

Culture methods. Tracheal secretions were cultured on Columbia agar with 5\% sheep blood (Heipha, Heidelberg, Germany) and on cetrimide agar (Heipha), whereas nasal, scalp, and throat swabs were cultured on sheep blood agar alonc. Rectal swabs were first subcultured on sheep blood agar plates and were then put into peptone water with cetrimide, which was subcultured on cetrimide agar plates the next day. All blood agars were incubated at $37^{\circ} \mathrm{C}$, whereas media containing cetrimide were incubated at $42^{\circ} \mathrm{C}$, both under aerobic conditions.

Environmental samples were inoculated on Columbia agar containing $0.5 \%$ Tween $80,0.07 \%$ lecithin, and $7 \%$ sheep blood (Heipha) and were incubated at $37^{\circ} \mathrm{C}$. Media were incubated for up to 2 days, and pigmented (pyocyanin or pyomelanin) colonies with cytochrome oxidase activity were transferred from blood to cetrimide agar. Strains were stored on trypticase soy agar at $20^{\circ} \mathrm{C}$ until typing was done. Water samples were aspirated through a cellulose filter membrane. One-half of this filter was placed on a blood agar plate and the other half on agar with cetrimide.

Ribosomal RNA gene ( $(D N A)$ restriction patterns. Isolates of $P$. aenginosa were regrown on $5 \%$ sheep blood agar, and one colony each was suspended in $5 \mathrm{~mL}$ of Luria Bertani broth at $37^{\circ} \mathrm{C}$. After incubation overnight, $1.5 \mathrm{~mL}$ was used for isolation of total DNA by a mini-prep procedure [6]. DNA samples were digested with eight restriction endonucleases, Pstl, $S_{m}$ II, EcoRI, $B c /$. HindlII, Clal, SphI, and Pvull (Boehringer, Mannheim, Germany), as recommended by the manufacturer. Fragments were then separated by electrophoresis through a $0.8 \%$ agarose gel in TRIS-borate-EDTA buffer (TBE; $0.089 M$ TRIS, $0.089 M$ boric acid, and $0.2 \mathrm{mM}$ EDTA, $\mathrm{pH} 8.0$ ), stained in ethidium bromide ( $1 \mathrm{~g} / \mathrm{mL}$ ), and photographed. Thereafter they were transferred to a nylon membrane (BiodyneA; Pall Biosupport, East Hills, NY) using a vacuum transfer apparatus (Pharmacia Biotechnology. Piscataway, N.I) at 50 mbar for $1 \mathrm{~h}$ with $20 \times$ SSC ( $3 M \mathrm{NaCl}, 0.3 M \mathrm{Na}$ citrate, $\mathrm{pH} 7.0$ ) as transfer solution. Prehybridization and hybridization were carried out at $42^{\circ} \mathrm{C}$ in $5 \times$ Denhardt's solution, $5 \times \mathrm{SSC}, 50 \mathrm{~m} M$ sodium phosphate buffer, $\mathrm{pH} 6.5,250 \mathrm{~g} / \mathrm{mL}$ denatured salmon sperm DNA, and $5 \%$ dextran sulfate. After prehybridization for $1 \mathrm{~h}$, the heat-denatured DNA probe (a pBR322-derived biotin-labeled plasmid pKK 3535 containing a ribosomal RNA operon of Escherichia coli) $[7,8]$ was added to fresh solution, and the filters were incubated overnight at $42^{\circ} \mathrm{C}$. The filters were washed and hybrids visualized by a chromogenic reaction using the BluGene kit (Bethesda Research Laboratories, Gaithersburg, MD).

\section{Results}

During the 4-month period, 4679 samples were collected and cultured, 1635 from patients, 2463 from personnel, and 581 from environmental sources. Only 18 (11.5\%) of 153 patients were colonized at single or multiple body sites with $P$. aeruginosa (table 1), 8 of them (44\%) being positive from their day of admission. Of this group, 4 patients had been admitted directly, whereas the other 4 were transferred from other hospitals or wards. Rectal swabs yielded the organism in a significantly higher proportion than nasal swabs or tracheal secretions, both in patients colonized from the beginning of their stay on the ICU (75\% vs. 63\% and 37\%) and in patients whose cultures were found positive only later on ( $70 \%$ vs. $30 \%$ and $30 \%$ ).

Among the samples collected from personnel, $P$. aeruginos $a$ was isolated three times from hands of personnel caring for different patients. Twice the organism was found on the emergency button from respirators, whereas tap water samples were always negative.

Fifty-one isolates from 18 patients and 3 isolates from hands of different nurses were investigated using restriction endonuclease analysis of rDNA. The 2 isolates from respirators could not be included because they had not survived several subculturing passages (table 1).

Discrimination between independent strains varied with the restriction enzymes used. It was lowest for $B c /$ II and very high for PvulI (table 1). Two endonucleases, $P_{S t} l$ and SmaI, were abandoned because of their low discriminatory power. $H$ indIII had to be excluded from the study because of incomplete digestion of the DNA and arbitrary restriction patterns that were interpretable with uncertainty only. The remaining five enzymes could easily distinguish 16 different groups of ribotypes, and 15 were separated by the use of restriction endonuclease PvuII alone (figure 1). The reproducibility of ribotypes was $100 \%$.

Each patient appeared to be colonized by 1 single strain; $14(78 \%)$ of 18 patients harbored $P$. aeruginosa types that had not been isolated from any other animate or inanimate source except for 2 cases (table 1), and only twice did 2 patients have the same ribotype. All environmental samples and samples from personnel remained single findings.

\section{Discussion}

Epidemiologic associations of $P$. aeruginosa strains have usually been based on a combination of serotyping as a primary screen and pyocin typing for additional discrimination [9]. However, the frequency of individual O types of P. aeruginosa in clinical specimens has varied with the country of investigation and the source of the isolate. In addition, $\sim 8 \%$ 
Table 1. Sources and rDNA patterns of isolates from an intensive care unit.

\begin{tabular}{|c|c|c|c|c|c|c|c|c|}
\hline \multirow{2}{*}{$\begin{array}{l}\text { Patient } \\
\text { no. }\end{array}$} & \multirow{2}{*}{$\begin{array}{l}\text { Isolation site of } \\
\text { P. armginosa } \\
\text { from patient }\end{array}$} & \multirow{2}{*}{$\begin{array}{l}\text { Isolation site of } P \text { aeruginosa } \\
\text { from environment and personnel }\end{array}$} & \multicolumn{5}{|c|}{ rDNA pattern with restriction enzyme } & \multirow[b]{2}{*}{ Ribotype } \\
\hline & & & $E c o \mathrm{RI}$ & $B c /$ II & $C l a l$ & $S p h I I$ & $P_{1 u I I I}$ & \\
\hline 1 & Rectum (1), tracheal secretion (1) & Emergency button of respirator ( 1$)^{*}$ & a & a & a & a & a & A \\
\hline 2 & Nose (1) & Hand of personnel (1) & a & a & a & a & a & A \\
\hline 3 & Rectum (2). decubitus (2) & None & b & a & c & $\mathrm{c}$ & $\mathrm{m}$ & $\mathrm{B}$ \\
\hline 4 & Pharynx (I) & Nonc & $b$ & $\mathbf{a}$ & c & $\mathrm{c}$ & $\mathrm{m}$ & B \\
\hline 5 & Tracheal secretion (5) & None & $d$ & a & $\mathrm{c}$ & a & $\mathrm{e}$ & $\mathrm{C}$ \\
\hline 6 & Rectum (1). drain (2) & None & a & a & c & $b$ & b & $\mathrm{D}$ \\
\hline 7 & Rectum (2), nose (5). drain (4) & $\begin{array}{l}\text { Hand of personnel }(1)^{\dagger} \text {, emergency } \\
\text { button of respirator }(1)^{*+\dagger}\end{array}$ & c & c & c & $\mathrm{b}$ & $f$ & $\mathrm{E}$ \\
\hline 8 & Recium (3) & None & $\mathrm{c}$ & a & $\mathrm{c}$ & a & k & $\mathrm{F}$ \\
\hline 9 & $\begin{array}{l}\text { Tracheal secretion ( } 3 \text { ), nose (1), } \\
\text { pharynx (1) }\end{array}$ & None & $\mathrm{e}$ & a & a & c & $g$ & $\mathrm{G}$ \\
\hline 10 & Rectum (1) & Hand of personnel (1) & a & a & $\mathrm{c}$ & e & $\mathbf{h}$ & $\mathrm{H}$ \\
\hline 11 & Rectum (1) & None & $\mathbf{a}$ & a & c & a & $\mathrm{i}$ & 1 \\
\hline 12 & Nose (1) & None & $\mathrm{c}$ & $\mathrm{b}$ & d & d & $p$ & $\mathrm{~K}$ \\
\hline 13 & Rectum (1). nose (1) & None & a & a & c & $\mathbf{a}$ & $\mathrm{c}$ & $\mathrm{L}$ \\
\hline 14 & Tracheal secretion (1) & None & a & a & b & a & $b$ & $\mathbf{M}$ \\
\hline 15 & Rectum (I) & None & $\mathrm{c}$ & $\mathrm{a}$ & a & c & 1 & $N$ \\
\hline 16 & Rectum (2) & None & a & $b$ & $c$ & d & $\mathrm{n}$ & $\mathrm{O}$ \\
\hline 17 & Rectum (1). nose (1) & None & a & a & $\mathrm{c}$ & $\mathrm{f}$ & 0 & $\mathrm{P}$ \\
\hline 18 & $\begin{array}{l}\text { Rectum (2), tracheal secretion (1). } \\
\text { nose (2), scalp (1) }\end{array}$ & None & a & a & a & b & $\mathrm{d}$ & $Q$ \\
\hline
\end{tabular}

NOTE. No. of isolates is in parentheses.

Not ribotyped.

Tositive 1 month before patieni's samples.

of clinical isolates react strongly with a pooled serum but fail to be agglutinated by individual ones [9]. Pyocin as well as phage typeability rates are high but of low reproducibility and discriminatory power, factors that affect the reliability of most typing methods in epidemiologic investigations of $P$. aeruginosa [10]. Biotyping is rarely helpful, and antibiograms of strains can give a useful guide to the identification of a problem strain, but specificity is low and unpredictable changes in sensitivity patterns, especially during outbreaks, may occur [9].

Novel approaches to the typing of $P$. aeruginosa, such as analysis of multilocus isoenzyme patterns [11] or molecular typing methods, have recently been developed. Genomic fingerprinting by field inversion gel electrophoresis [12] and restriction fragment length polymorphism analysis in the exotoxin A [4, 13] or pilin [14] region has been shown to significantly enhance discrimination compared with that achieved by former methods [15]. However, different serotypes. biotypes, and antibiograms may be genetically indistinguishable $[10,13]$. Ribosomal DNA polymorphisms have been used successfully to distinguish between individual strains in a variety of bacteria, and recently $P$. aeruginosa strains from cystic fibrosis patients were analyzed using this method [11].

The present study used the plasmid pKK3535 probe, which encodes a ribosomal RNA operon consisting of the genes for 5S RNA, 16S RNA, 23S RNA, and tRNA giv [7].
The sensitivity of the method is highly dependent on the restriction enzymes used to digest chromosomal DNA [8]. The best discrimination among our strains was provided by restriction endonuclease $P$ will, which separated 15 of 18 strains (figure 1, table 1). The relatively low sensitivity of rDNA restriction patterns cited by other authors [11] is most probably a result of insufficient searching for appropriate endonucleases.

The fact that 16 ribotypes were obtained from 18 unrelated patients (table 1) suggests that except for 2 cases, no cross-infections took place. We presume that gastrointestinal carriage of $P$. aeruginosa with numbers below the threshold of detection was present before hospital admission, as suggested also by others [2]. Antibiotic pressure and total digestive decontamination, which alter the barrier effect of the normal intestinal flora [12], were therefore probably the reason for endogenous acquisition of $P$. aeruginosa.

Only twice we assumed that a strain was passed from one patient to another by an undetected carrier. These nondistinguishable strains were harbored by patients who followed each other in the same room (patients 1 and 2) or who were cared for at the same time on the ward (patients 3 and 4). Since standards of hygiene are more likely to fail when the unit is busy, cross-infection may have taken place. Environmental contamination could be proven in the first case, as $P$. aeruginosa was isolated from the nurse's hand as well as from 


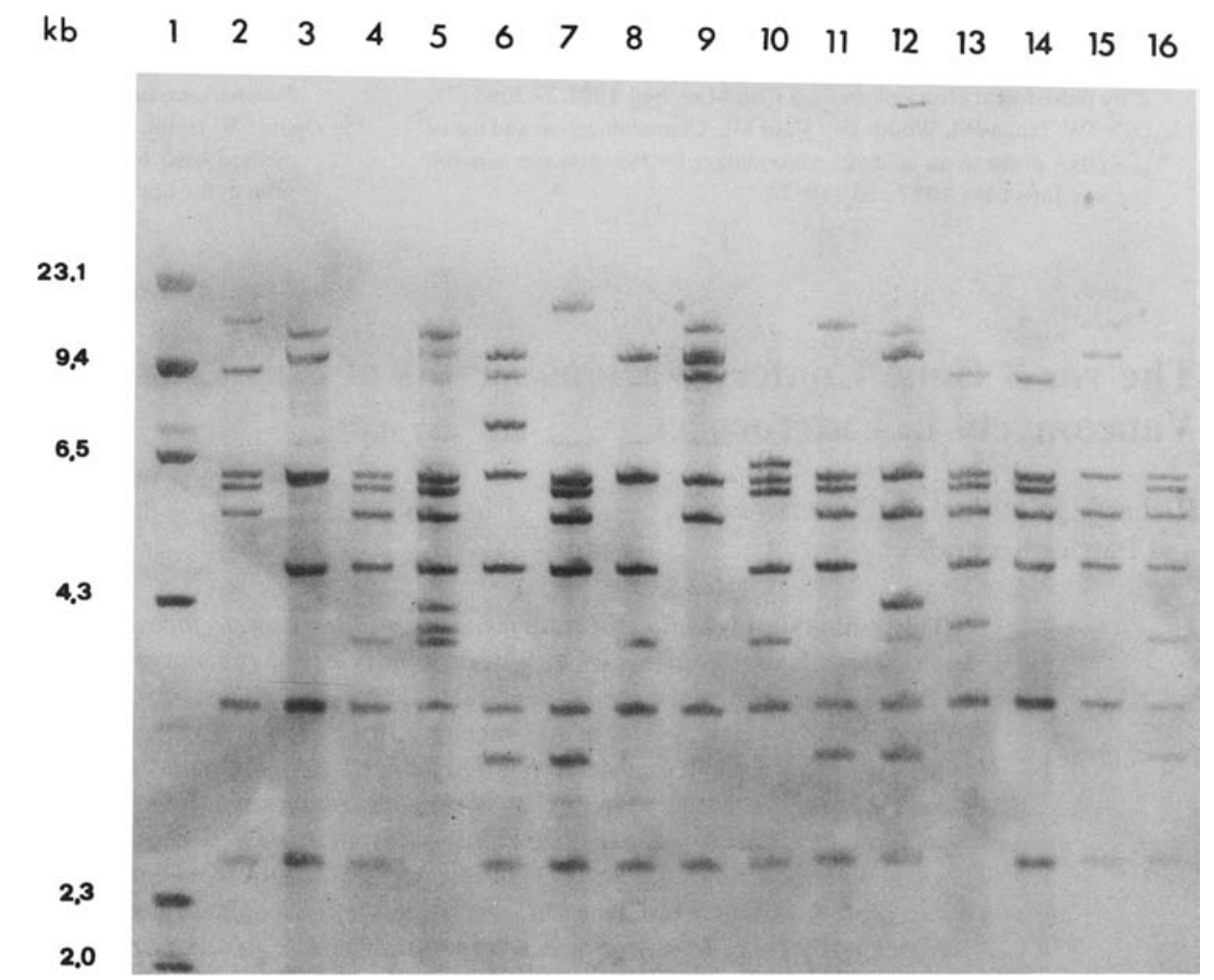

Figure 1. rDNA patterns of $P$ acruginosa strains (digestion with Pvull). Lane 1: Molecular weight marker, $\lambda$ DNA digested with HindIII: lanes 2-16: 15 different ribotypes after digestion with PvuIl. the respirator (table 1). Longitudinal sampling of $P$. aeruginosa from patients, personnel, and the environment of hospitals in other studies has revealed that up to $42 \%$ of the personnel may have positive hand cultures and that in some cases $P$. aeruginosa genotypes were isolated from sinks before they were isolated from hands of personnel or patients' specimens [4]. As the staff is generally considered responsible for transmission of bacteria within the $\mathrm{ICU}$, the number of positive specimens (3) from personnel as well as from other environmental samples during this study was surprisingly low. Equally, the organism could not be isolated from water sources at all, although water reservoirs have been shown to harbor most nosocomial strains $[2,4]$.

Many studies have implicated horizontal transmission as an important problem. However, the detection of a wide spectrum of different ribotypes, the fact that $44 \%$ of the strains were already present on admission, and their low presence in the environment suggest that endogeneous colonization rather than nosocomial acquisition had occurred.

\section{References}

1. Morrison A.J, Wenzel RP. Epidemiology of infections due to Pseudomonas arenginosa. Rev Infect Dis 1984:6(suppl 3):627-42.

2. Olson B. Weinstein RA. Nathan C, Chamberlin W. Kabins SA. Epidemiology of endemic Pseudomonas aenginosa: why infection control efforts have failed. J Infect Dis 1984;150:808-16.
3. Teres D. Schweers P, Bushnell LS, Hedley-Whyte J, Feingold DS. Sources of Pseudomonas aeniginosa infection in a respiratory/surgical intensive care unit. Lancet 1973:1:415-7.

4. Döring G, Ulrich M, Müller W, et al. Generation of Pseudomonas aerzginosa aerosols during hand-washing from contaminated sink drains, transmission to hands of hospital personnel, and its prevention by use of a new heating device. Zentralbl Hyg Umweltmed 1991:191:494-505.

5. Noone MR, Pitt TL. Bedder M. Hewlett AM. Rogers KB. Psetdomonas aeruginosa colonization in an intensive therapy unit: role of cross infection and host factors. Br Med J 1983:286:341-4.

6. Ausubel FM, Brent R. Kingston RE, et al. Current protocols in molecular biology. Chichester, UK: John Wiley \& Sons, 1989.

7. Brosius J. Ullrich A. Raker MA, et al. Construction and fine mapping of recombinant plasmids containing the $\mathrm{rr}$ B ribosomal $\mathrm{RNA}$ operon of Escherichia coli. Plasmid 1981;6:112-8.

8. Martinetti $G$. Altwegg M. rRNA gene restriction patterns and plasmid analysis as a 1001 for typing Salmmella enteritidis. Res Microbiol 1990; 141:1151-62.

9. Pitt TL. Epidemiological typing of Pseudomonas aeruginosa. Eur J Clin Microbiol Infect Dis 1988;7:238-47.

10. Ojeniyi B, Wolz C, Doring G, Lam JS, Rosdahl VT, Hoiby N. Typing of polyagglutinable Pseudomonas aeruginosa isolates from cystic fibrosis patients. APMIS 1990:98:423-31.

11. Denamur E. Picard B. Goullet P. Bingen E. Lambert N. Elion J. Complexity of Pseudemonas caenginosa infection in cystic tibrosis: combined results from estcrase elcctrophoresis and rDNA restriction fragment length polymorphism analysis. Epidemiol Infect 1991; 106:531-9.

12. Boukadida J, De Montalembert M. Gaillard JL. et at. An outbreak of 
gut colonization by Pseudomonas aeruginosa in immunocompromised children undergoing total digestive decontamination: analysis by pulsed-field electrophoresis. J Clin Microbiol 1991;29:2068-71.

13. Ogle JW, Janda JM, Woods DE, Vasil ML. Characterization and use of a DNA probe as an epidemiologic marker for $P$ seudomonas aeruginosa. J Infect Dis 1987;155:119-26.
14. Speert DP. Campbell ME. Farmer SW, Volpel K, Joffe AM, Paranchy W. Use of a pilin gene probe to study molecular epidemiology of Psewdomonas acriginosa. J Clin Microbiol 1989:27:2589-93.

15. Ojeniyi B. Haiby N, Rosdahl VT. Genome fingerprinting as a typing method used on polyagglutinable Pseudomonas aeruginosa isolates from cystic fibrosis patients. APMIS 1991;99:492-8.

\title{
The vanB Gene Confers Various Levels of Self-Transferable Resistance to Vancomycin in Enterococci
}

\author{
Richard Quintiliani, Jr., ${ }^{*}$ Stefan Evers, \\ and Patrice Courvalin
}

Unité des Agents Anribactériens, Institut Pasteur, Paris, France

\begin{abstract}
Thirty-nine strains of Enterococcus fuecium and Enterococcus faecalis resistant to vancomycin and susceptible to teicoplanin on disk susceptibility testing (phenotypic class B) were isolated in 15 hospitals in Europe and the United States. The MICs of vancomycin for these strains ranged from 4 to $1024 \mu \mathrm{g} / \mathrm{mL}$. Part of the vancomycin resistance gene vanB from E. faecalis V583 hybridized with a single but variably sized HindIII-KpnI fragment of total DNA from all 39 strains. This indicates that a single class of resistance determinants accounts for the Van B phenotype. No hybridization was detected with DNA from intrinsically resistant Enterococcus gallinarum or Enterococcus casseliflavus. Hybridization with DNA from enterococcal strains susceptible to or with acquired resistance to vancomycin and teicoplanin was not observed. The genes conferring resistance to vancomycin were self-transferable to other Enterococcus strains in 14 of the 39 strains. It thus appears that $\operatorname{van} B$ confers various levels of conjugative vancomycin resistance in enterococci.
\end{abstract}

Glycopeptide antibiotics (vancomycin and teicoplanin) bind to the peptidyl-D-alanyl-D-alanine termini of peptidoglycan precursors and block their incorporation into the bacterial cell wall [1]. Resistance to glycopeptides in clinical isolates of enterococci can be classified by the level of resistance to vancomycin and susceptibility or resistance to teicoplanin [2]. Three classes of resistance (A, B, and C) have been distinguished.

The class A phenotype comprises strains of Enterococcus faecium and Enterococcus faecalis with high-level resistance to vancomycin (MIC $\geqslant 64 \mu \mathrm{g} / \mathrm{mL}$ ) and teicoplanin (MIC $\geqslant 16 \mu \mathrm{g} / \mathrm{mL}$ ). Resistance is inducible by vancomycin or teicoplanin and is often mediated by self-transferable plasmids [2]. High-level glycopeptide resistance in these strains is associated with the acquisition of genes related to $\operatorname{van} A$ [2]. This gene encodes a D-alanine-D-alanine ligase of modified

Received 17 November 1992; revised 28 December 1992.

Reprints or correspondence: Prof. P. Courvalin, Unité des Agents Antibactériens, Institut Pasteur, 25 rue du Docteur Roux, 75724 Paris Cedex 15. France.

* Present affiliation: Infectious Diseases, Columbia University, New York City.

The Journal of Infectious Diseases 1993;167:1220-3

(c) 1993 by The University of Chicago. All rights reserved

$0022-1899 / 93 / 6705-0038 \$ 01.00$ specificity that synthesizes peptidoglycan precursors with reduced affinity for glycopeptide antibiotics [3].

Class B consists of strains of E. faecalis and E. faecium inducibly resistant to low levels of vancomycin (MIC 8-64 $\mu \mathrm{g} / \mathrm{mL}$ ). These strains remain susceptible to teicoplanin $(\mathrm{MIC} \leqslant 1 \mu \mathrm{g} / \mathrm{mL}$ ), although vancomycin induces resistance to this antibiotic. Resistance of this class is thought not to be transferable, with the corresponding determinant tentatively assigned a chromosomal location [2].

Class C includes the majority of Enterococcus gallinarum and Enterococcus casseliflavus isolates constitutively resistant to low levels of vancomycin (MICs $\geqslant 8$ and $\leqslant 32 \mu \mathrm{g} / \mathrm{mL}$ ) and susceptible to teicoplanin ( $\mathrm{MIC} \leqslant 1 \mu \mathrm{g} / \mathrm{mL}$ ). Resistance in these species appears intrinsic, as all the isolates examined to date are resistant [4]. Resistance is not transferable by conjugation and is thought to be chromosomal [2]. Vancomycin resistance in $E$. gallinarum is associated with the presence of nucleotide sequences related to van C [4], a gene that shares similarity with vanA [5].

Recently, another class of glycopeptide resistance in enterococci isolated in the United States has been suggested [6]. Strains of E. faecium and E. faecalis with this phenotype are highly resistant to vancomycin (MIC $\geqslant 128 \mu \mathrm{g} / \mathrm{mL}$ ) but remain susceptible to teicoplanin. The resistance is inducible by vancomycin but not by teicoplanin and, in certain isolates, is transferable by conjugation [7]. 